\title{
La educación superior en el contexto de la posmodernidad: Entendimiento y reconciliación
}

\section{Higher Education in a Context of Postmodernity: Understanding and Reconciliation}

\author{
Luis Guillermo Barrantes Montero \\ Escuela de Literatura y Ciencias del Lenguaje \\ Universidad Nacional, Costa Rica \\ luisba66@yahoo.es
}

Recibido 01 de diciembre de 2010 • Aceptado 09 de marzo de 2011

Resumen. El propósito de este trabajo es fomentar la reflexión y la toma de conciencia acerca de la necesidad y conveniencia de buscar un mayor acercamiento entre los docentes, las autoridades y los estudiantes universitarios con respecto al modo en que se concibe la educación superior en el momento actual, su razón de ser y sus metas. Para ello, se compara la perspectiva modernista y postmoderna de la sociedad y de la educación, a fin de evidenciar los principales puntos de divergencia y los posibles canales de consenso. Se concluye proponiendo la apertura de espacios para lograr acuerdos de intersubjetividad y, así, alcanzar el objetivo propuesto.

Palabra claves. Posmodernismo, educación superior, relativismo, libertad de cátedra.

Abstract. This paper aims at promoting reflection and awareness about the need of a closer understanding among professors, authorities and university students on how higher education (purpose and goals) is perceived today. The study compares the Modernist and Postmodern perspectives of society and education, in order to identify the main points of divergence, as well as the possible ways of consensus. As a conclusion, new spaces are proposed to find intersubjectivity agreements, as a way to achieve the objective stated.

Keywords. Postmodernism, higher education, relativism, freedom of speech.

"Todo el que es de la verdad escucha mi voz. Le dice Pilato: ¿Y qué es la verdad?"

Jn. 19, 37-38

\section{Introducción}

Una constatación frecuente entre muchos docentes universitarios de hoy es la profunda brecha entre lo que para ellos es el objetivo y la razón de ser de la enseñanza universitaria y lo que los estudiantes, las políticas de Estado y la sociedad actual están demandando de ella sin, al parecer, poder hacer algo para disminuirla. Al hablar de "muchos" docentes, se pretende reconocer que también

\footnotetext{
Profesor propietario en la Escuela de Literatura y Ciencias del Lenguaje de la Universidad Nacional, Costa Rica.
} 
existen aquellos que procuran readecuar su contribución profesional a los desafíos que impone el momento presente y plantear espacios de acercamiento con miras al futuro. Estos últimos son los que, tanto en nuestro entorno inmediato costarricense como también en muy diversas latitudes y, gracias a los medios de información que en la actualidad se tienen a disposición, articulan las ideas que contribuyen a establecer puentes para acortar esa separación.

El presente trabajo pretende compendiar, de algún modo, el camino recorrido por esos profesores en cuanto a la concienciación y comprensión del tema y, a la vez, proponer líneas de acción para que sean cada vez más los académicos que compartan esta visión.

Entre las situaciones que los docentes constatan como evidencia de esa discordancia entre sus esquemas académicos y su contraparte, los actores sociales involucrados en el proceso educativo, se puede subrayar el frecuente desinterés por cualquier tipo de conocimiento que no tenga aplicación práctica e inmediata. Los muy laureados académicos lamentan el hecho de que el saber ya no se busca per se, sino sólo en función de alguna utilidad. En segundo lugar, destaca la presión administrativa -movida por las autoridades del Estado- para maximizar los esfuerzos en función de los números, de la productividad y de los requerimientos del sector productivo y financiero, sea este nacional o transnacional. En tercer lugar, y en un sitio más inmediato, los docentes perciben, en sus clases, que los estudiantes cada vez son más reacios a reconocer principios de verdad objetivos, sus metas son escasas, sus líderes y modelos de identificación son efímeros y sus valores parecen haber dado un giro bastante pronunciado con respecto a los de una o dos generaciones anteriores. Lo más interesante en este último sentido es que, a la vez, estos mismos estudiantes, que al parecer se muestran escépticos ante todo lo que se les proponga, manifiestan ya sea sutil, ya sea abiertamente, un anhelo y una necesidad de encontrar un sentido más profundo a su existencia, una sed de hallar algo que trascienda esa frugalidad, algo realmente incuestionable por lo que merezca la pena vivir. Paradójicamente, los mensajes que continuamente reciben, por parte de la propaganda comercial y por los reportes noticiosos, les refuerzan el sentir de que las cosas no pueden ser de otra forma y que no queda más remedio que acomodarse a vivir con ello. Una manera aparentemente decorosa de lidiar con el asunto, para ellos, consiste en acudir a la educación como una manera de adquirir destrezas tecnológicas para entrar en lo que, quizá sin advertirlo, los encamina a un círculo interminable de producción y consumo de bienes y servicios. Este círculo es plenamente justificado por los tecnócratas actuales que rigen los destinos de los pueblos pues, según ellos, el motor de la economía es el consumo de todo lo que se produce y, en esa misma lógica, cuanto más vacío se encuentre un individuo en su existencia personal, mayor será su tendencia al consumo de productos para intentar saciarse de algún modo. Así, muchos individuos adquieren conductas compulsivas, pues la avidez por adquirir cosas no responde a necesidades reales sino a otras que les han sido creadas. Sin un propósito integral, que les permita ver la vida como un proyecto, los nuevos graduados de las universidades se lanzan al mundo del trabajo a formar parte de esa sociedad convulsa, competitiva e insolidaria, y que le plantea grandes sombras a su futuro.

Los docentes universitarios de corte tradicional, por su parte, formados en épocas en las que se atesoraba el conocimiento como tal y posicionados en sus "torres de marfil" como depositarios del saber, no parecen tener más remedio que lamentar el hecho de que las nuevas generaciones se les vayan de las manos. Se convierten en una "voz que clama en el desierto". Algunos de estos docentes perciben que sus tan respetadas disciplinas en otros tiempos, ya han perdido vigencia, interés y sentido; se han quedado sin audiencia, sus aulas están vacías y sus escritos ya no se leen. Otros; sin embargo -y esto es particularmente real en Costa Rica-, dada la afinidad de sus campos de 
especialización con las demandas del "supermercado global", se avienen afanosamente a construir un modelo de universidad transformada en centros de entrenamiento de destrezas, en instituciones de preparación de trabajadores relativamente bien pagados, aunque carentes de formación integral. Para esos docentes, se trata simplemente de aprovechar el momento y contemporizar con la "moda" en educación. Ese modelo de universidad es el más apreciado en el mundo de la globalización, en lo que se denomina hoy la era de la información. Con esto último, se designa el gran paso que ha dado la humanidad para convertir el acervo de conocimiento y los datos de información de su forma física tradicional, impresa en papel, a su forma digitalizada, conservada y manejable mediante ordenadores electrónicos conectados a una red planetaria. Gracias a esa red de conexiones, los seres humanos tienen acceso casi ilimitado al saber; aunque, paradójicamente, por la misma razón se ha ensanchado la brecha entre ricos y pobres: hoy se habla de analfabetismo informático, en referencia a quienes no tienen acceso a la tecnología computacional.

Los académicos que han analizado con cierto grado de profundidad el problema, a fin de delinear un planteamiento propositivo, contrastan el estilo de enseñanza tradicional con la exigencia del momento presente y distinguen entre la perspectiva modernista o positivista, y la perspectiva postmoderna del saber, de la formación y de la transmisión del conocimiento. Las páginas que siguen intentarán ilustrar ese contraste y proponer líneas de reconciliación. Resulta imperativo que en las universidades se asigne la importancia que tiene el tema y se trabaje con eficacia para obtener un norte en el planteamiento y la consecución de sus objetivos.

\section{Visiones modernista (positivista) y posmoderna acerca del conocimiento y de la sociedad}

Al introducir este tema, conviene citar a Nguyen (2010), en su distinción entre positivismo modernista y el postmodernismo:

Mientras el modernismo ha sustentado sus principios en la razón y las metanarrativas y ha ensalzado y preconizado la verdad de la ciencia y la tecnología, el posmodernismo rechaza tales logros científicos que han traído tantos beneficios como desastres para la vida y ha ensanchado la estratificación social (...). La educación modernista ha preparado a los jóvenes para la ciudadanía y para los puestos de trabajo fijos, mientras la educación posmoderna parece entrenar a los jóvenes para las incómodas incertidumbres y para vivir en el caos. (Nguyen, 2010 , p. 88$)^{2}$

La cita anterior pone las cartas sobre la mesa, en el hecho de que en los centros de educación superior no se está asistiendo a un simple capricho en los comportamientos de la población sino que, con tales comportamientos, subyacen cosmovisiones bien delineadas y bastante antagónicas. No obstante, aunque por un lado se puede proponer una definición clara de lo que es el modernismo y sus raíces, en el caso del postmodernismo no es tan sencillo. Por Modernismo se entiende aquí un movimiento estético de finales del siglo XIX y principios del XX, el cual se identifica con el progreso de la ciencia y la posesión táctica de la verdad. Durante el siglo XX se acentuó el carácter innegable que comporta la verdad científica y el avance tecnológico. La verdad de los postulados modernistas se presenta como diáfana y evidente; lo ha sido así para el mundo académico, para el sector productivo y la esfera política.

\footnotetext{
Las citas textuales que aparecen en este trabajo fueron traducidas por el autor desde el original inglés.
} 
Más aún, con la caída de los grandes regímenes totalitarios, a finales del siglo XX, parece haberse consolidado una serie de verdades incuestionables, entre ellas, que el futuro del mundo está en un orden económico espontáneo, o sea, la economía de mercado; que ese orden debe estar enmarcado dentro de un sistema de convivencia social que garantice la protección de la iniciativa particular, es decir, la democracia; que el conocimiento, mediante el desarrollo de la ciencia y la tecnología, es la alternativa única para llevar a la sociedad a aquel estado ideal de satisfacción al que cada uno de sus miembros aspira. Esto es, que la educación esté al servicio de un engranaje social práctico en el que todo lo que se produzca, se consuma. Se origina, de esta manera, una generación continua de empleos para que cada individuo se desarrolle a plenitud; y que, en el plano de la espiritualidad, la prosperidad económica es la señal inequívoca de que se está en buenos términos frente a lo trascendente. Esto último es un dato de muy frecuente difusión en los medios masivos de hoy.

Definir el Posmodernismo es algo complejo. En términos de la sensibilidad post moderna, ni siquiera es posible. Según Leicester, evocando a Usher y Edwards (1994): "las definiciones y las prescripciones prácticas son incompatibles con la perspectiva posmoderna" (Leicester, 2000, p. 73). Se le distingue más bien por el conjunto de elementos en común surgidos a partir de sus reacciones en contra de la soberanía de la ciencia, de la hegemonía de las tradiciones y "verdades" occidentales y de la autoridad epistemológica de los sistemas políticos establecidos.

A continuación se presenta un cuadro comparativo de los principios más generales de la visión modernista y postmodernista del conocimiento y de la sociedad. Como base en los argumentos se exponen algunas ideas de académicos como Chi Hong Nguyen, planteadas en su artículo "The Changing Postmodern University" y en el artículo "Postmodernism and Continuing Education, de Leicester (2000):

\begin{tabular}{|c|c|}
\hline Perspectiva modernista (positivista) & Perspectiva posmoderna \\
\hline $\begin{array}{l}\text { 2.1a Racionalidad del saber: Gracias a los avances de la } \\
\text { ciencia, se logra fundamentar el razonamiento científico } \\
\text { y filosófico en las reglas de la naturaleza y no en mitos } \\
\text { y creencias como en la antigüiedad. El individuo humano } \\
\text { posee autonomía e identidad, a diferencia de la antigua } \\
\text { creencia de la contingencia debida al pecado original. }\end{array}$ & $\begin{array}{l}\text { 2.1b Escepticismo ante el saber: Todo lo que } \\
\text { hasta ahora se ha entendido como conocimiento y } \\
\text { principios de verdad objetivos son solo constructos } \\
\text { humanos. La identidad del yo y de la sociedad son } \\
\text { conceptos relativos y sujetos a la interpretación y } \\
\text { manipulación de todo aquel que ejerce alguna cuota } \\
\text { de poder para usarlos a su favor. }\end{array}$ \\
\hline $\begin{array}{l}\text { 2.2a Legitimidad del orden social: La sociedad se fun- } \\
\text { damenta en el orden y la organización. La sostenibilidad } \\
\text { depende de las leyes de convivencia que están plena- } \\
\text { mente establecidas. El papel del gobierno no es el de un } \\
\text { benefactor del pueblo, sino más bien el de una especie } \\
\text { de árbitro que garantiza que las decisiones de unos indi- } \\
\text { viduos no lesionen los intereses de otros individuos. El } \\
\text { estado de derecho es plenamente suficiente para garanti- } \\
\text { zar eso y para dirimir cualquier desavenencia que surja } \\
\text { entre los individuos, ya que el Derecho también tiene la } \\
\text { objetividad de una disciplina científica. }\end{array}$ & $\begin{array}{l}\text { 2.2b Legitimar la dominación: Las culturas } \\
\text { eurocentristas han monopolizado la noción de } \\
\text { "verdad" y consideran ortodoxas todas sus políticas } \\
\text { y sus axiomas a favor de la dominación, con el } \\
\text { desdén de la perspectiva de otras culturas y formas } \\
\text { de pensar. Los estados, desde un inicio organizados y } \\
\text { liderados por representantes de grupos hegemónicos } \\
\text { desdeñan el aporte y desatienden las necesidades } \\
\text { de los menos favorecidos. La población que se } \\
\text { asienta y se multiplica en la periferia no recibe } \\
\text { ninguna evidencia de que ser alguien ante los ojos } \\
\text { de los potentados. Por ello, el modelo de Estado } \\
\text { tradicional está en crisis y no puede reclamar } \\
\text { ninguna credibilidad. }\end{array}$ \\
\hline
\end{tabular}

Continúa... 


\begin{tabular}{|c|c|}
\hline Perspectiva modernista (positivista) & Perspectiva posmoderna \\
\hline $\begin{array}{l}\text { 2.3.a. Derivaciones prácticas de la racionalidad: De } \\
\text { una epistemología centrada en la razón surge el concepto } \\
\text { de la centralidad del individuo, tanto en el plano material } \\
\text { como en la espiritualidad. En la esfera política, esto es } \\
\text { lo que sostiene la democracia liberal; en el plano eco- } \\
\text { nómico, de ahí se sustenta el capitalismo y la lógica del } \\
\text { mercado. }\end{array}$ & $\begin{array}{l}\text { 2.3.b. ¿El saber al servicio de quién? La sensibi- } \\
\text { lidad posmoderna se orienta a la colectividad, a la } \\
\text { identificación con los menos favorecidos del siste- } \\
\text { ma social y con la preocupación por la conservación } \\
\text { del entorno. El progreso económico a expensas del } \\
\text { deterioro de la humanidad y de su hábitat, en vez de } \\
\text { ser un éxito, ha devenido en un fracaso. }\end{array}$ \\
\hline $\begin{array}{l}\text { 2.4.a. Generación y expansión del saber: Los grandes } \\
\text { avances de las disciplinas científicas articulan los saberes } \\
\text { en un corpus transmisible mediante el sistema educativo } \\
\text { y va creciendo conforme se agregan nuevos descubri- } \\
\text { mientos y nuevas invenciones. La tecnología evoluciona } \\
\text { irrefrenablemente, incluso a una velocidad mayor a la } \\
\text { de las demandas de los usuarios. Nunca como hoy se } \\
\text { disfruta de la posibilidad de acceder al conocimiento sin } \\
\text { fronteras. Todo saber que se genera mediante rigor cien- } \\
\text { tífico es y debe tenerse como válido independientemente } \\
\text { del lugar en donde se esté. }\end{array}$ & $\begin{array}{l}\text { 2.4.b. La pluralidad de perspectivas del saber: } \\
\text { Se debe reconocer y se debe validar una pluralidad } \\
\text { de perspectivas en todo lo que converge en el ser } \\
\text { humano. En este contexto, se alienta y se promue- } \\
\text { ve una forma de pensar más bien ecléctica, dando } \\
\text { cabida a la diversidad. Ninguna propuesta, ninguna } \\
\text { cosmovisión debe ser negada a priori. Todas las } \\
\text { propuestas y todas las cosmovisiones proceden de la } \\
\text { interpretación que alguien le ha dado a determinado } \\
\text { fenómeno o cuestionamiento. Ahora no hay cabida } \\
\text { para los dogmatismos y, si algo ha sido considerado } \\
\text { dogma durante algún tiempo, ahora hay que decir } \\
\text { que el dogma evoluciona y, como tal, está sujeto } \\
\text { también a una pluralidad de interpretaciones. }\end{array}$ \\
\hline $\begin{array}{l}\text { 2.5.a. El fundamento de la verdad: El modernismo } \\
\text { plantea tres verdades fundamentales: Primero, que } \\
\text { existe un mundo real, el cual determina nuestro esquema } \\
\text { conceptual y, por ende, la base de lo verdadero se ubica } \\
\text { fuera de nuestra conceptualización. Segundo, ese mundo } \\
\text { real nos provee de datos que nosotros identificamos } \\
\text { y nombramos, pero que no dependen ni son relativos } \\
\text { a nuestra interpretación. Tercero, cualquier esquema } \\
\text { conceptual que no se ajuste a la realidad objetiva no es } \\
\text { posible; o bien, está equivocado. }\end{array}$ & $\begin{array}{l}\text { 2.5.b. No hay verdad sin contexto: En la posmo- } \\
\text { dernidad hay una gran preocupación por el lenguaje } \\
\text { y por la interpretación de las palabras y de los } \\
\text { textos. El anti-esencialismo posmoderno consiste } \\
\text { en el no reconocimiento de las metanarrativas. Los } \\
\text { textos, como toda estructura significante, tienen } \\
\text { una amplia gama de significados e interpretaciones. } \\
\text { La verdad no está fuera de la historia al estilo del } \\
\text { "Hiper-urano" platónico. No hay un "punto de } \\
\text { apoyo" al estilo de Arquímedes, solo hay contexto, } \\
\text { variables e interpretación. La verdad es relativa y } \\
\text { priva la incertidumbre. }\end{array}$ \\
\hline
\end{tabular}

Quiérase o no, la sociedad de hoy vive inmersa dentro de esta dicotomía. En cada individuo hay algo de ambas partes. Algunas de nuestras acciones están regidas por pensamientos positivistas, mientras otras reflejan nuestra influencia posmoderna. Los centros de educación superior no escapan a esta realidad. Aunque se cree tener muy claro el concepto de "universidad", bien puede hablarse de "pluridiversidades". Las distintas autoridades de cada facultad toman decisiones emanadas desde ambas vertientes. Los docentes, con o sin conciencia de ello, llevan a la clase lo que hay en ellos de cada una de esas perspectivas y los estudiantes, a su vez, construyen su perfil académico y profesional con el mismo influjo.

Las preguntas que conviene plantearse ante el panorama anterior son -entre otras-: ¿Le conviene a la academia ignorar la existencia de esa dicotomía y simplemente continuar como está? ¿Se sugiere más bien que cada cual deba optar por una de las dos visiones y conducirse según ella, creándose así dos bandos; uno, el de los que tienen un talante positivista y otro, el de los que optan 
por una sensibilidad postmoderna? ¿A nivel de individuos, deberemos sacudir de nosotros uno de los dos enfoques y reafirmar el otro para no sentirnos como seres contradictorios? ¿Qué evidencia hay de que esa oposición se esté dando en los centros académicos? ¿A lo mejor se está juzgando a las universidades de un defecto que no tienen? ¿Acaso sus actores no habrán alcanzado ya un grado de madurez tal que puedan conducirse por encima de esos "fantasmas" que sólo asustan a los menos ilustrados?

Para saber si tales interrogantes merecen una respuesta, conviene continuar con la tabla comparativa entre ambas perspectivas, pero esta vez con referencia a la educación superior. En este caso, se recogen algunas ideas del profesor Nicholas M. Strohl, de la Universidad de Cambridge, en su artículo "The Postmodern University Revisited: Reframing Higher Education Debates, From "the two cultures" to Postmodernity", (Strohl, 2006).

\section{Visión modernista (positivista) y posmoderna acerca de la educación superior}

\begin{tabular}{|c|c|}
\hline Perspectiva modernista (positivista) & (Perspectiva posmoderna) \\
\hline $\begin{array}{l}\text { 3.1.a. Propósito de la educación: En palabras del lla- } \\
\text { mado humanista liberal, el profesor R. Leavis, el valor } \\
\text { intrínseco de la educación universitaria es "producir } \\
\text { ciudadanos responsables, libres y reflexivos para una } \\
\text { sociedad moderna" (citado por Strohl, 2006, p. 135). }\end{array}$ & $\begin{array}{l}\text { 3.1.b. Educación e identidad social: El posmo- } \\
\text { dernismo rechaza la idea de que la educación con- } \\
\text { sista en desarrollar las habilidades cognitivas del } \\
\text { individuo a fin de que se inserte plenamente en la } \\
\text { sociedad como ciudadano productivo; más bien se } \\
\text { busca promover la plena identidad social de ese ser } \\
\text { humano. }\end{array}$ \\
\hline $\begin{array}{l}\text { 3.2.a. Cultivar al individuo: El pensamiento pre- } \\
\text { moderno se afianzaba en creencias, sobre todo en la fe } \\
\text { en una entidad sobrenatural que dirige el destino del } \\
\text { mundo. En la época de la modernidad, se exalta el valor } \\
\text { del individuo y de la ciencia (Hicks, 2004). Los métodos } \\
\text { educativos buscan acercar el individuo a ese acervo de } \\
\text { saberes para que se desarrolle como tal. }\end{array}$ & $\begin{array}{l}\text { 3.2.b. Cultivar la preocupación colectiva: Los } \\
\text { métodos educativos se ejercen por la vía del len- } \\
\text { guaje. De este modo, se desarrolla en el ciudadano } \\
\text { una sensibilidad social, racial y sexual, a la vez que } \\
\text { se opone a todo tipo de opresión. No se acepta el } \\
\text { discurso de que la iniciativa individual o el conjun- } \\
\text { to de ellas pueda, a la larga, producir una sociedad } \\
\text { libre de conflictos y de desigualdades generadoras } \\
\text { de estos. }\end{array}$ \\
\hline $\begin{array}{l}\text { 3.3.a. La mente se ajusta a la verdad: Desde la época } \\
\text { de la ilustración se reconoce la objetividad de la evidencia } \\
\text { científica. En el plano de la individualidad, el yo humano } \\
\text { construye su esquema de conocimiento a partir de los } \\
\text { datos que se le presentan como principios universales. El } \\
\text { papel de la academia es, por ello, entrenar y preparar las } \\
\text { mentes del estudiantado para que pueda relacionar los } \\
\text { datos que llega a conocer y de ese modo aprenda a cons- } \\
\text { truir su propio método de conocimiento e incluso pueda } \\
\text { generar nuevos conocimientos que habrá de compartir } \\
\text { con la comunidad del saber. Como apuntó Philip Altback } \\
\text { (citado por Tierney, 2001, p. 153), "el conocimiento es } \\
\text { internacional". }\end{array}$ & $\begin{array}{l}\text { 3.3.b. La "verdad" está sujeta a la interpreta- } \\
\text { ción: El conocimiento, cualquiera que sea, puede } \\
\text { construirse en la mente de las personas, y no se } \\
\text { le valora porque sea hallado cierto, sino porque } \\
\text { se le considera útil a un propósito (Delashmutt \& } \\
\text { Braund, citados en Nguyen, 2010). Lo que se enseña } \\
\text { en las escuelas no es una verdad como tal, sino un } \\
\text { producto construido por alguien, y es "un asunto de } \\
\text { poder", como diría Foucauld, 1977. Para este autor, } \\
\text { el conocimiento se ha convertido en una mercancía } \\
\text { y los países que controlan el conocimiento poseen } \\
\text { una mayor cuota de poder. }\end{array}$ \\
\hline
\end{tabular}

Continúa.. 


\begin{tabular}{|c|c|}
\hline Perspectiva modernista (positivista) & (Perspectiva posmoderna) \\
\hline $\begin{array}{l}\text { 3.4.a. La especialización del individuo: La mejor } \\
\text { organización y la maximización de los esfuerzos en la } \\
\text { educación superior consisten en el fortalecimiento de } \\
\text { las disciplinas científicas y en sus especializaciones. Así } \\
\text { cada individuo puede orientar sus esfuerzos de aprendi- } \\
\text { zaje hacia una meta clara y definida dentro de un campo } \\
\text { específico del saber. Lo contrario sería invertir recursos } \\
\text { limitados a proveer a los alumnos con conocimientos que } \\
\text { no les serán de utilidad dentro de su profesión. }\end{array}$ & $\begin{array}{l}\text { 3.4.b. La integración de saberes: El énfasis curri- } \\
\text { cular en las disciplinas refuerza el "elitismo" aca- } \\
\text { démico. Por un lado, ese elitismo relega ciertos } \\
\text { saberes a un segundo plano por considerárseles } \\
\text { como de poca aplicabilidad práctica. Los saberes } \\
\text { que no generan riqueza material o no tienen una } \\
\text { utilidad inmediata como lo son las disciplinas que } \\
\text { fomentan el pensamiento crítico, la formación de } \\
\text { valores personales y cívicos, son eclipsados por las } \\
\text { ciencias prácticas. Por otro lado, ese mismo elitismo } \\
\text { excluye a los grupos menos favorecidos del acceso } \\
\text { al conocimiento. }\end{array}$ \\
\hline $\begin{array}{l}\text { 3.5.a. Quizá falta adicionar algún ingrediente: La } \\
\text { perspectiva modernista positivista reconoce, ciertamente, } \\
\text { que los esfuerzos realizados por la ciencia han generado } \\
\text { una disparidad en las metas de desarrollo de la huma- } \\
\text { nidad. Se ha adelantado admirablemente en algunos } \\
\text { campos; mientras que se ha producido un estancamiento } \\
\text { en otros, en especial, en cuanto al desarrollo humano. } \\
\text { Además, se constata que un buen sector de las sociedades } \\
\text { se muestra reacio a participar en el mundo del progreso, } \\
\text { pese a la oferta de oportunidades educativas. Surge así la } \\
\text { duda de si la superación de tales carencias está en aplicar } \\
\text { más ciencia y más tecnología o se requiere del algo más. }\end{array}$ & $\begin{array}{l}\text { 3.5.b. El ingrediente faltante es el reconoci- } \\
\text { miento de la diversidad: Por todo lo anterior, la } \\
\text { perspectiva posmoderna de la educación busca un } \\
\text { eclecticismo de la academia. Ningún enfoque por } \\
\text { sí solo ha logrado ni logrará dar respuesta a todas } \\
\text { las necesidades urgentes a solventar para los seres } \\
\text { humanos. La negación total de las metanarrativas } \\
\text { y el anti-fundacionalismo defendido a toda costa, } \\
\text { demandan sin duda una apertura al reconocimiento } \\
\text { pluricultural de los modos de ver el mundo y la } \\
\text { educación de las gentes. Solo la síntesis de nuevas } \\
\text { perspectivas puede traer una respuesta concreta a } \\
\text { los faltantes que se constatan y a la deuda que las } \\
\text { sociedades tienen consigo mismas. }\end{array}$ \\
\hline
\end{tabular}

Los cuadros comparativos anteriores ofrecen un panorama bastante claro, aunque no exhaustivo, de las visiones y las implicaciones que conlleva cada una de las perspectivas. Resulta imperativo reconocer que nuestros centros académicos en la actualidad operan y se manejan en medio de esa dualidad. Ante eso, conviene analizar el tema y valorar si los académicos deben realizar una conciliación entre ambas posturas o si más bien se acepta que cada quien ofrezca sus aportes desde una de las dos ópticas; la cual, a su vez, quiérase o no, nunca podrá considerarse como cien por ciento pura, ya que estará sesgada por la influencia de la perspectiva opuesta. Decidirse por esta última opción le ocasionaría perjuicios al individuo, a las instituciones educativas y a la sociedad, al menos a mediano o a largo plazo. Por ejemplo, la desproporcionalidad ocasionada por una fe ciega en la superación de la pobreza y de la marginalidad, apostando radicalmente por el éxito científico y el empleo de la tecnología -es decir, inclinando la balanza totalmente hacia el lado positivista-, sin atender las demás dimensiones del ser humano y de su entorno, aceleraría el proceso de despersonalización, de vacío existencial y de una pérdida del sentido de la vida, que, a la larga, sumiría en un estado colectivo de decadencia y decepción, precisamente en el mismo momento cuando, en apariencia, se constate una mayor prosperidad a nivel macroeconómico. Eso habrá sido así, porque tal prosperidad se habría generado manteniendo ocultas otras realidades a las que, por mucho tiempo, se había optado por no atender. Baste para ello, las experiencias vividas por algunos países industrializados.

$\mathrm{Si}$, por otro lado, se opta por ceder enteramente ante el escepticismo posmodernista, se daría una acentuación del relativismo, del caos, de la anarquía -llamada hoy ingobernabilidad-, de la 
indisciplina e, igualmente, de la sensación de sin sentido de la vida. La preocupación posmoderna, tan afanosamente citada para defender los intereses de los menos favorecidos de la sociedad, no pasará de ser un mero discurso romántico, pues la falta de un principio y fundamento ordenador de la sociedad y del modo de producción, no ayudaría en nada a la generación de nueva riqueza y, por ende, a la disminución de la pobreza. Tampoco eliminaría la injusticia, pues la validez ilimitada de todas las perspectivas y modos de pensar alentaría nuevas formas injustas. El dejarse llevar por la decepción producida por un sistema imperante que no funciona, sin tener una alternativa propositiva y basada en una decisión de atender metas concretas y permanentes, posiblemente, igualaría a todos al nivel de los menos favorecidos, sin tener en cuenta el hecho de que en el mundo entero, $\mathrm{y}$ a lo largo de la historia, los pueblos más aventajados se aprovechan de los menos y los someten de diversas maneras, ya sea explícitas o sutiles. Los pueblos que se dejan llevar por el caos y el devenir se vuelven víctimas de los pueblos disciplinados. Por ello, el fin de un período de colonización no significa necesariamente el fin de la amenaza colonial. Las nuevas formas del colonialismo pueden ser quizá más difíciles de vencer, pues son establecidas a tenor del Estado de Derecho, se articulan en tratados internacionales y en la legalización de prácticas restrictivas del comercio o en los mecanismos legales que permiten el despojo de lo que, hasta cierto momento, se había considerado como derechos irrenunciables de los pueblos. Esos recursos habrán pasado al dominio privado y, para acceder a ellos, se deberá pagar el canon establecido por el neo colonizador. Mientras esas cosas ocurren en la sociedad, el mundo académico se encuentra dividido: unos afanados al servicio de la inmediatez y de la razón práctica, y otros convencidos de la idea de que, en los tiempos actuales, todo se tolera, pues son los tiempos de la diversidad; y algunos otros, fosilizados en sus dogmas tradicionales. Ante ello, se hace necesario un acercamiento entre los miembros de los cuerpos docentes para compartir puntos de vista y alcanzar puntos de convergencia y de consenso. Entonces, la universidad podrá aportar planteamientos sólidos y unificados a la sociedad, según esta se los demanda.

Por su parte, los estudiantes universitarios de hoy, aunque ignoren la dialéctica teórica entre el positivismo modernista y el posmodernismo, navegan en ambos mares de forma simultánea. Por un lado, se adentran con ilusión en el afán de las ciencias y de los recursos tecnológicos, visualizan el futuro promisorio que les garantiza el obtener un título superior y manifiestan tener fe en el Estado y sus instituciones. Por otra, saben que hay evidencias que traicionan esas convicciones. La consecución de puestos de trabajo suele estar condicionada por influencias que no tienen que ver con la idoneidad y la preparación académica; la corrupción patente a todo nivel no garantiza un ambiente de seguridad para desplegar sus anhelos de vida. El pensar en tener que salir de las aulas para hacerse tragar por un sistema que no parece mejorar se ha convertido en un tabú del que no se quiere ni se debe hablar. Asumen también, de esta manera, conductas relativistas, postmodernas: entienden que es necesario convivir con el caos, hasta donde los lleve la corriente en boga. Son escépticos ante todo criterio de verdad, ante propuestas políticas, ante la espiritualidad, ante la posibilidad de tomar decisiones permanentes. Por ejemplo, si una realidad humana como lo es el amor, debe considerarse como una decisión de la voluntad y no como un mero sentimiento, no lo creen posible, pues hoy no se garantiza las sostenibilidad de las decisiones.

Tenemos, entonces, el efecto de la dualidad tanto entre los académicos como en el estudiantado. Parece estar claro y algunos dirían que no hace falta resaltarlo. Sin embargo, cuando este problema se les plantea a los académicos, no tarda en surgir la prevención de que cada cual es libre de pensar, actuar y enseñar como lo considere mejor. ¿Es posible, entonces, conciliar la libertad de cátedra con la colegialidad académica? Muchos docentes manifiestan no estar dispuestos a ceder un ápice de esa libertad en el ejercicio de la docencia. No ven, sin embargo, que la mutua comunicación 
puede llevarlos a identificar puntos de convergencia y jerarquías de criterios en temas centrales, aunque las formas de expresión y las derivaciones prácticas de los mismos puedan ser diversas. Si se considera oportuno y conveniente conciliar la mentalidad modernista positivista y la posmoderna, se debe llegar primero a esa convergencia de que la unidad entre libertad de cátedra y colegialidad académica es posible. La comunicación entre el cuerpo docente puede establecer puentes para compartir principios comunes. A continuación se ofrecen dos modelos para ese acercamiento:

La autora Leicester recurre a Wittgenstein en cuanto a lo que él denominó "acuerdos de intersubjetividad" (Leicester, 2000, p. 79). Tales acuerdos subyacen bajo los diversos juicios que emiten los sujetos y hacen posible el consenso. Leicester da su punto de vista así: "Mi propia posición epistemològoco metafísica..." (Leicester, 2000, p. 79):

Mi propia posición epistemológico-metafísica es la de un relativismo limitado, que combina el potencial normativo del modernismo - mejor / peor; bien / mal; verdadero/ falso- con la flexibilidad del postmodernismo - pluralidad de perspectiva, no dogmatismos y la eliminación de fronteras-. También evito la proclamación de verdades trascendentales, por la contradicción que ellas conllevan, ya que lo único que conocemos del mundo es por conceptos mediados... Por ello no hay duda de que en nosotros existen conceptos universales (valores, criterios de sentido común, etc.) y conceptos locales. Un ejemplo de ello es la experiencia universalmente reconocida de la traductibilidad de los lenguajes humanos, pero a la vez, la imposibilidad de su traductibilidad local es también prueba de la variación local de los conceptos... quizá como educadores debemos aprender a reconocer formas universales de la experiencia humana y del conocimiento sin imponer valores y conocimientos locales al modo etno-céntrico y neocolonialista.

El segundo modelo es propuesto por Strohl (2006), para el cual es necesario plantear una tercera vía entre el vacío que genera el relativismo cultural postmoderno y la tendencia al instrumentalismo positivista. Esa tercera vía la denomina el "cosmopolitanismo" -para efectos de la conciliación entre dos conceptos de cultura- y la "comunalidad" -referente a la producción del conocimiento-. La idea de cosmopolitanismo la toma de Hollinger (1995) y la de comunalidad, de Habermas (1987).

Según Hollinger, la educación superior tiene un papel cultural y social importante. Por un lado, está el movimiento multicultural que propone defender las fronteras culturales y ubicar a los individuos dentro de su respectivo grupo etno-racial, el cual se hereda y debe ser protegido. Por otro lado, está el temor postmoderno a abordar el tema de la cultura dados los prejuicios que este conlleva. La tercera vía entre esas posiciones se funda en la diversidad, pero no con base en la etnicidad, la raza o el género, sino en identidades culturales y sociales dinámicas y abiertas. El cosmopolitanismo se muestra a favor de "afiliaciones voluntarias".

Para Habermas (1987), en cuanto a la producción del conocimiento, "la situación ideal del discurso" es aquella en la que todos los participantes se tratan como iguales y la comunicación está orientada a un entendimiento común de la verdad, donde se llega a un consenso por el recurso al mejor argumento y no apelando a la autoridad ni a cualquier otra imposición.

La noción de cosmopolitanismo de Hollinger y la de comunalidad de Habermas plantean un reto tanto a la universidad, como a la sociedad moderna, en cuanto a cómo reconciliar la tensión entre la diversidad cultural y social, las oportunidades económicas y la necesidad de un concepto consensuado de ciudadanía, responsabilidad y compromiso social. (p. 145) 


\section{Conclusión}

En este artículo se ha esbozado el tema de la educación superior en el contexto de la posmodernidad. Se ha expuesto la experiencia constatada por los docentes universitarios de la disparidad y falta de consonancia entre los contenidos de sus disciplinas y las demandas de la sociedad actual, lo mismo que la reacción de sus estudiantes. Se ha hecho uso de las conclusiones de diversos investigadores en el tema, a fin de proponer unas líneas de comprensión del problema en nuestro contexto particular y un modo de buscar puntos de convergencia entre las dos perspectivas que se han señalado: la positivista modernista y la posmoderna.

Entre las propuestas se citó el ejemplo del cosmopolitanismo y la comunalidad, propuestos por el profesor Strohl, de la Universidad de Cambridge, y el concepto de acuerdos intersubjetivos, de la profesora Mal Leicister.

Esta reflexión ha pretendido contribuir con las instituciones de educación superior en su tarea de dar a conocer los diversos criterios existentes y llegar a puntos de consenso para que los estudiantes, a su vez, adquieran un saber unificado. En palabras de Nguyen (2010, p. 92):

El aprendizaje de lo social construye en los estudiantes la conciencia de ser ciudadanos y su participación cívica. El aprendizaje académico los involucra en el entendimiento y la aplicación de diversos tipos de conocimiento, de manera crítica y analítica.

El autor de este artículo se ha planteado la cuestión de si es posible conciliar libertad de cátedra y colegialidad. Con los ejemplos anteriores ha intentado sugerir que sí es posible. No obstante, el tema de cómo definir y poner en práctica esa colegialidad, sin duda será tema de un estudio posterior.

\section{Referencias bibliográficas}

Habermas, J. (1987). The Philosophical Discourse of Modernity: twelve lectures [El discurso filosófico y la modernidad: Doce conferencias]. Cambridge, MA; MIT Press.

Hicks, S. (2004). Explaining Postmodernism: Skepticism and Socialism from Rousseau to Foucault [Explicación del postmodernismo: Escepticismo y socialismo, de Rousseau a Foucault]. Arizona: Scholargy Publishing.

Hollinger, D. (1995). Postethnic America: Beyond Multiculturalism [La América post-étnica: Más allá del multiculturalismo]. New York: Basic Books.

Leicester, M. (2000, enero-febrero). Post-Postmodernism and Continuing Education [El postmodernismo y la educación continua]. International Journal of Lifelong Education, 19(1), 73-81.

Nguyen, C. (2010, August). The Changing of Postmodern University [La cambiante universidad postmoderna]. International Education Studies, 3(3), 88-99. Recuperado de http://www. ccsenet.org/journal/index.php/ies/article/view/6052/5300 
Strohl,N.(2006). The Postmodern University Revisited: Reframing Higher Education Debates from the 'two cultures' to postmodernity [Revisitando la universidad postmoderna: Un replanteamiento de los debates en torno a la educación superior de las "dos culturas" a la postmodernidad]. London Review of education, 4(2), 133-148. doi: 10.1080/14748460600855195

Tierney, W. G. (2001). The Autonomy of knowledge and the Decline of the Subject. Postmodernism and the Reformulation of the University [La autonomía del conocimiento y la mengua del sujeto. El postmodernismo y la reformulación de la universidad]. Higher education, 41(4), 353-372. doi: 10.1023/A:1017588907541

Usher, R. y Edwards, R. (1994). Postmodernism and education [El postmodernismo y la educación]. London: Routledge.

Wittgenstein, L. (2003). Tractatus Logico-Philosophicus [Tratado lógico-filosófico]. Madrid, Spain: Alianza. 